That the efferent limb of the "clubbing reflex" may be humoral is suggested by observations of hormonal factors being associated with clubbing. Patients with bronchial carcinoma and hypertrophic pulmonary osteoarthropathy have been reported to have raised concentrations of growth hormone. ${ }^{3}$ Clubbing has also been described in association with a case of thyroid carcinoma and primary hyperparathyroidism. ${ }^{4}$ Lam et al reported two cases (in brothers) with pachydermatoperiostosis, hypertrophic gastropathy, and complicated duodenal ulcers. ${ }^{5}$ In these cases the serum concentrations of gastrin were normal but concentrations of pepsinogen 1 and 2 were raised.

The clubbing associated with the Zollinger-Ellison syndrome in our patient, which regressed after resection of the tumour, was probably due to some substance produced by the tumour. Gastrin itself was unlikely to be the substance, as vagotomy, which may abolish clubbing, is often associated with raised serum concentrations of gastrin. Moreover, tumours such as gastrinomas, which are from the APUD cell series, are known to secrete many peptides, only some of which have been characterised.

1 Hall GH, Laidlaw CD'A. Further experimental evidence implicating reduced ferritin as a cause of digital clubbing. Clin Sci 1963;24:121-6.

Flavell G. Reversal of pulmonary hypertrophic osteoarthropathy by vagotomy. Lancet 1956;i:260 Steiner H, Dahlback OV, Waldenstrom J. Ectopic growth hormone production and osteoarthropathy in carcinoma of the bronchus. Lancet 1968 ;i: $783-5$

4 Richards AJ. A case of thyroid carcinoma and primary hyperparathyroidism with pseudoclubbing Brf Clin Pract 1971:25:34-6.

5 Lam SK, Hui KK, Ho J, Wong KP, Rotter JI, Samloff IM. Pachydermatoperiostosis, hypertrophic gastropathy and peptic ulcer. Gastroenterologv 1983;84:834-9.

Accepted 26 August 1986

Professorial Surgical Unit, St Stephen's Hospital, London SW10

M TAUBE, BSC, FRCS, senior surgical registrar

C WASTELL, MS, FRCS, professor of surgery

Correspondence to: Professor Wastell.

\section{Neuropsychiatric complications related to use of prazosin in patients with renal failure}

Although postural hypotension and syncope are well known side effects of prazosin, neuropsychiatric complications have rarely been recorded. We report on three neuropsychiatric patients who recovered completely after the drug was withdrawn.

\section{Case reports}

Case 1-A 63 year old housewife who had been receiving continuous ambulatory peritoneal dialysis for one year for diabetic renal failure was admitted because of impaired drainage of peritoneal dialysate. She also had hypertension, diabetic retinopathy, and peripheral and autonomic neuropathy. Her blood pressure was not well controlled despite treatment with metoprolol, and prazosin was started and increased to $2 \mathrm{mg}$ three times daily. Over the next four weeks she became confused and suffered from visual hallucinations and paranoid ideas. No significant biochemical changes occurred, however, and her autonomic dysfunc tion did not change. An electroencephalogram showed intermittent diffuse slow wave abnormality, which was consistent with metabolic encephalopathy. Prazosin was stopped, and she recovered over eight weeks.

Case 2-A 70 year old woman with a 15 year history of diabetes mellitus stabilised by glibenclamide was admitted after three weeks of intermitten drowsiness, confusion, and uninhibited behaviour such as undressing. She also had longstanding hypertension, treated initially with methyldopa, but prazosin $5 \mathrm{mg}$ three times daily had been started six weeks previously for better control. Over the past year she had developed diabetic renal failure, with urea concentration $19 \cdot 6$ (normal 3-8) $\mathrm{mmol} / \mathrm{l}(117 \cdot 6(18-48) \mathrm{mg} / 100 \mathrm{ml})$ and creatinine concentration $280(50-120) \mathrm{umol} / \mathrm{l}(3 \cdot 17(0 \cdot 57-1 \cdot 36) \mathrm{mg} / 100 \mathrm{ml})$. She was afebrile and had no focal neurological deficit. There was no evidence of hypoglycaemia or postural hypotension, and cerebrospinal fluid composition and results of other biochemical investigations were normal. Over the next few days her mental state fluctuated, and an electroencephalogram was performed, which showed diffusely abnormal trace with no focal features. We suspected that this might be related to prazosin, which was stopped over the next three days; her mental state improved dramatically. Two months after discharge her mental state and behaviour were normal, and a repeat electroencephalogram showed great improvement.

Case 3-A 40 year old man with a 20 year history of insulin dependent diabetes and hypertension was admitted because of sudden left hemiparesis. Computed tomography of his head showed a lacunar infarct in the right internal capsule. While in hospital he had two grand mal seizures, controlled with phenytoin.
Prazosin $2 \mathrm{mg}$ three times daily was also started because his blood pressure was not well controlled with methyldopa alone. His hemiparesis improved gradually and he returned home. He was readmitted two weeks later, however, because of psychotic behaviour. He was paranoid, with signs of organic psychosis, strong delusions of grandeur, and hallucinations. There was no biochemical evidence of hypoglycaemia or phenytoin toxicity, and an electroencephalogram showed intermittent slow waves over the right hemisphere, compatible with the vascular lesion. His renal function was mildly impaired, but it remained stable throughout his psychosis. Prazosin was stopped and the hypertension controlled with metoprolol. The psychosis was settled with a short course of chlorpromazine and trifluoperazine. Eight months after discharge and withdrawal of the major tranquilliser paranoia had not recurred.

\section{Comment}

We think that the increased abnormalities in the central nervous system in our three patients were due to prazosin, because their chronic renal failure might have affected the clearance of prazosin.

The results of pharmacokinetic studies in chronic renal failure are not yet consistent, ${ }^{12}$ though the $50 \%$ increase in the free fraction of prazosin observed in patients with chronic renal failure ${ }^{3}$ might explain the apparent association of central nervous system toxicity with renal failure. Animal studies also support the observation that prazosin could be responsible for the abnormal symptoms of the central nervous system. ${ }^{4} 5$

We advise the cautious use of prazosin in patients with renal failure. The Committee on Safety of Medicines and the drug manufacturer have told us about one notification of paranoia and five of hallucination since 1974 .

1 Graham RM, Thornell JR, Gain JM, Bagnoli C, Oates HF, Stokes GS. Prazesin: the first dose phenomenon. Br Med f 1976;ii:1293-4.

2 Lowenthal DT, Hobbs D, Affrime MB, Twomey TM, Martinez EW, Onesti G. Prazosin kinetics and effectiveness in renal failure. Clin Pharmacol Ther 1980;27:779-83.

3 Rubin P, Blaschke T. Prazosin protein binding in health and disease. Br $\mathrm{f}$ Clin Pharmacol 1980;9:177-82

4 Morrow LA, Battaglia G, Norman AB, Creese I. Identification of subtypes of $\left[{ }^{3} \mathrm{H}\right]$ prazosin-labelled $\alpha_{1}$ receptor binding site in rat brain. Eur f P harmacol 1985;190:285-7.

5 Pichler L, Kobinger W. Possible function of $\alpha_{1}$-adrenoceptors in the CNS in anaesthetised and conscious animals. Eur f Pharmacol 1985; 107:305-11.

Accepted 4 August 1986)

Department of Medicine, United Christian Hospital, Kwun Tong, Kowloon, Hong Kong

D K F CHIN, FRACP, neurologist

A K C HO, MB, BS, medical officer

C Y TSE, MRCP, medical consultant

Correspondence to: Dr Chin.

\section{Epidural methadone for preoperative analgesia in patients with proximal femoral fractures}

Proximal femoral fracture in elderly patients is one of the most common fractures seen in the orthopaedic department. The treatment of choice is internal fixation, and a delay in performing the operation or contraindication to surgery creates problems in the nursing of patients. The optimal time for preoperative assessment, preparation, and medical stabilisation of these patients is about 12 to 24 hours. ${ }^{1}$ Before and after surgery such patients are prone to pain, pressure sores, pneumonia, thromboembolic phenomena, and central depression caused by systemic narcotics.

Epidural analgesia induced by opiates is an accepted method of pain relief after surgical orthopaedic intervention. ${ }^{2}$ Epidural methadone has the same analgesic potency as morphine but fewer complications; urinary retention is rarely seen, and respiratory depression has not been reported. We evaluated prospectively the effect of continuous epidural analgesia induced by methadone in patients with fractures of the femoral neck.

\section{Patients, methods, and results}

Twelve patients (seven women and five men, age range 21-93 (mean 68.9)) sustained proximal femoral fractures and were treated surgically by hemiarthroplasty or Richard's sliding compression nail. Epidural analgesia was started soon after clinical and radiological evaluation in the emergency room. We added $4 \mathrm{ml}$ of methadone hydrochloride $0 \cdot 1 \%$ to $6 \mathrm{ml}$ of saline and injected this through the epidural catheter. The severity of the pain was evaluated subjectively before and two hours after the injection as follows: no pain $=0$, mild pain $=1$, and severe 
pain $=2$. Pain was evaluated with patients $(a)$ supine, $(b)$ supine with the leg being moved, $(c)$ sitting on a bed, $(d)$ sitting in a chair, and $(e)$ being moved from bed to chair.

Blood pressure, heart rate, frequency of respiration, urinary output, and blood gases were measured every two hours during the first 12 hours and then four times a day.

The mean pain score dropped from 9.5 (SE 2.5 ) before injection of methadone to $5.4(2.5)$ after injection. Six patients received injections once a day, five received injections twice a day, and one received injections three times a day. Operations took place from one to 16 days after admission (mean 4.4 days). Epidural analgesia was stopped between one and seven days after the operation (mean $3 \cdot 1$ days). No patient could be transferred from bed to chair before treatment because of severe pain. After analgesia was induced by methadone only three patients could not be transferred and all could change position in bed. One patient had urinary retention and had to have a catheter inserted. Five patients had a urinary catheter before the first injection. The remaining six patients passed urine within the first four to six hours after analgesia was induced. No change in blood pressure, frequency of breathing, or arterial blood gases was noted.

\section{Comment}

Patients with proximal femoral fracture usually experience severe pain. Pain relief is, however, difficult as the systemic use of narcotics in elderly patients is limited because of side effects. ${ }^{3}$ Methadone provides excellent analgesia with a lower rate of complications than the systemic use of morphine. ${ }^{45}$ The fact that an average of $6 \mathrm{mg}$ of methadone daily produced the desired effect in our patients with a longer duration of action than has been reported may be attributed to the age of our patients.

Preoperative analgesia induced by epidural methadone facilitates early mobilisation and better nursing of patients and may thus prevent some of the well known complications experienced by patients with proximal femoral fractures.

1 Kenzora JE, Mccarthy RE, Bowell JD, Sledge CB. Hip fracture mortality. Relation to age, treatment, preoperative illness, time of surgery and complication. Clin Orhop 1984;186:45-56. 2 Lanz E, Theiss D, Riess W, Sommer V. Epidural morphine for postoperative analgesia: a doubleblind study. Anesth Analg 1982;61:236-40.

3 Goodman LS, Gilman AG. The pharmacological basis of therapeutics. 7th ed. New York: Macmillan, 1980:497-520

4 Cousins MT, Mather LE. Intrathecal and epidural administration of opiates. Anesthesiology $1984 ; 61(5): 276-310$

5 Evron S, Samueloff A, Simon A, Drenger B, Magora F. Urinary function during epidural analgesia with methadone and morphine in post caesarean section patients. Pain 1985;23:135-44.

(Accepted 1 September 1986)

Hadassah Medical Center, Einkerem, Jerusalem

M NYSKA, MD, department of orthopaedic surgery

B KLIN, MD, department of orthopaedic surgery

Y SHAPIRA, MD, department of anaesthesiology

B DRENGER, MD, department of anaesthesiology

F MAGORA, MD, department of anaesthesiology

G C ROBIN, FRCS, department of orthopaedic surgery

Correspondence to: Dr M Nyska, Department of Orthopaedic Surgery, Hadassah University Hospital, PO Box 12000, 91120 Jerusalem, Israel.

\section{Incidence of chickenpox in adults and recruitment of plasma donors for manufacture of zoster immunoglobulin}

Chickenpox is usually a minor childhood complaint but may cause a severe, life threatening infection in immunosuppressed patients. Passive immunisation using high titres of zoster immunoglobulin. may prevent severe infection in subjects who have been in contact with chickenpox or shingles. ${ }^{1-3}$ Healthy blood donors with high titres of circulating antibody to chickenpox virus provide the plasma for the manufacture of zoster immunoglobulin.

We studied the annual incidence of chickenpox in adults in a semirural general practice of 11000 patients and assessed whether these convalescent adults would be suitable as donors of specific antizoster plasma.

\section{Patients, methods, and results}

Eleven adults were diagnosed as having chickenpox over a year. They were asked to provide blood samples at diagnosis and six weeks and one year after the onset of the rash.
Titres of antibody to chickenpox virus were assayed at the protein fractionation centre using an indirect immunofluorescence antibody assay. ${ }^{4}$ Plasma donations $\mathbb{D}$ are considered acceptable for fractionation at a titre of $1 / 32$ or greater.

The table shows patient details and serial antibody titres. Of the 11 patients, eight $(74 \%)$ achieved a titre of at least $1 / 32$ within six weeks of diagnosis. In contrast, of the eight patients tested one year after infection, none were found to have acceptable antibody titres.

Zoster antibody titres in the 11 patients

\begin{tabular}{|c|c|c|c|c|c|}
\hline \multirow[b]{2}{*}{ Case No } & \multirow[b]{2}{*}{ Sex } & \multirow[b]{2}{*}{ Age (years) } & \multicolumn{3}{|c|}{ Titre } \\
\hline & & & Initial & After 6 weeks & After a year \\
\hline 1 & $\mathbf{F}$ & 34 & $>32$ & $>32$ & 8 \\
\hline 2 & $\mathbf{M}$ & 21 & 8 & $>32$ & 16 \\
\hline 3 & $\mathrm{~F}$ & 22 & $>32$ & 16 & 8 \\
\hline 4 & $M$ & 21 & 4 & $>32$ & 8 \\
\hline 5 & $\mathbf{F}$ & 22 & 4 & $>32$ & - \\
\hline 6 & F & 22 & 4 & 16 & - \\
\hline 7 & $M$ & 21 & 4 & 16 & 8 \\
\hline 8 & $M$ & 43 & $>32$ & 16 & 8 \\
\hline 9 & $\mathbf{F}$ & 27 & $>32$ & 16 & 8 \\
\hline 10 & $\mathbf{M}$ & 20 & 4 & $>32$ & 8 \\
\hline 11 & $\mathbf{M}$ & 25 & 16 & 8 & - \\
\hline
\end{tabular}

Comment

Although most adults are immune to chickenpox, in one general practice of 11000 patients we found 11 convalescent patients who were willing to $\vec{\omega}$ provide specimens for measurement of antibody titres after infection with $\perp$ chickenpox. All were otherwise fit, healthy adults who would be eligible as donors of plasma, with the hope that they might continue with routine 0 donation after their antizoster titres had dropped.

There are two ways of obtaining plasma for the manufacture of zoster $N$ immunoglobulin: the testing of plasma donations selected at random or the $Z$ follow up of donors recently convalescent from chickenpox or shingles. 余 Random testing of donations is inefficient; in Scotland Cuthbertson et al $\frac{\Phi}{3}$ found only $0.7 \%$ of randomly selected donations to have a titre of $1 / 32$ or greater. ${ }^{4}$ Antibody titres in donors identified in this way do, however, tend to $\frac{\mathbb{C}}{-}$ be highly persistent. ${ }^{5}$ This study showed that, in contrast, $74 \%$ of patients $\vec{\theta}$ convalescing from chickenpox provided one or more acceptable plasma donations within six weeks of diagnosis. These acceptable antibody titres did not, however, persist, and when retested one year after diagnosis none of $\square$ these potential plasma donors still retained acceptable antibody titres. This confirms the findings of Hejias et al, who reported that the complement fixation titres of blood donors with a recent history of chickenpox waned fairly quickly. ${ }^{5}$

Almost all healthy adults with chickenpox are seen by a general $\stackrel{\varrho}{\vec{\alpha}}$ practitioner. This survey shows that a single practice can identify sufficient $\overrightarrow{\vec{O}}$ potential plasma donors to make a considerable contribution to the supply of 3 antizoster plasma. Arguably, it is the general practitioner's duty to encourage these patients to donate their immune plasma for the benefit of immunocompromised patients. The demand for such plasma varies, however, from region to region in the blood transfusion service. We suggest that interested general practitioners should contact their regional blood transfusion centre for advice on the requirements for the recruitment of zoster plasma donors.

1 Zaia JA, Levin MJ, Preblud SR. The status of passive immunisation for herpes virus infections. In: Alving BM, Finlayson JS, eds. Immunoglobulins: characteristics and uses of intravenous preparations. Washington: United States Department of Health and Human Services, 1980:111-21. 2 Wisnes R. Efficiency of zoster immunoglobulin in prophylaxis of varicella in high-risk patients. N

3 Meyers JD, Witte JJ. Zoster immune-globulin in high-risk children. $\mathcal{F}$ Infect Dis 1974;29:616-8. 4 Cuthbertson B, Hart W, Sommerville RG. Rapid random-donor screening for the selection of viral antibody containing donations. Ann Clin Res 1980;12:105-8.

5 Hejias M, Salker R, Barbara JAJ. Screening blood donors for high titre antibody to herpes varicella $\mathrm{N}$ zoster. Vox Sang 1980;39:335-8.

(Accepted 4 September 1986)

Newarthill, Motherwell ML1 5SP

DUNCAN C MACINNES, MB, MRCGP, general practitioner

Scottish National Blood Transfusion Service Protein Fractionation Centre, Edinburgh EH17 7QT

BRUCE CUTHBERTSON, BSC, PHD, quality assurance manager

Glasgow and West of Scotland Blood Transfusion Service, Law Hospital,
Carluke, Lanarkshire ML8 5ES

ROBERT J CRAWFORD, MB, MRCPATH, consultant

Correspondence to: Dr MacInnes. 